\title{
CHAPEUZINHO VERMELHO EM TRÊS VERSÕES: ANÁLISE DE GÊNERO NA PERSPECTIVA SISTÊMICO-FUNCIONAL ${ }^{1}$
}

\section{CAPERUCITA ROJA EN TRES VERSIONES: ANÁLISIS DE GÉNERO DESDE LA PERSPECTIVA SISTÉMICO-FUNCIONAL}

\author{
LITTLE RED RIDING HOOD IN THREE VERSIONS: GENRE ANALYSIS IN THE SYSTEMIC \\ FUNCTIONAL PERSPECTIVE
}

Cristiane Fuzer*

Sabrine Weber**

Universidade Federal de Santa Maria

\begin{abstract}
RESUMO: Este trabalho focaliza o funcionamento da linguagem em instanciações de gêneros da família das estórias, de acordo com a abordagem sistêmico-funcional de gênero (MARTIN; ROSE, 2008 e ROSE; MARTIN, 2012), que se fundamenta em princípios da Gramática Sistêmico-Funcional (HALLIDAY; MATTHIESSEN, 2004; 2014). Para demonstrar como funções léxico-gramaticais e semântico-discursivas evidenciam a instanciação de gêneros, foram analisados e comparados três textos que compartilham o propósito de envolver leitores/ouvintes: os clássicos Chapeuzinho Vermelho, nas versões de Charles Perrault, no século XVII, e dos Grimm, no século XX, e uma versão reinventada dessa estória em contexto escolar em 2012. A análise dos sistemas de transitividade e avaliatividade, que contribuem para realizar as etapas de gênero em cada texto, evidenciou duas instanciações do gênero narrativa, cujo propósito é resolver uma complicação, e uma instanciação do gênero exemplum, cujo propósito é julgar caráter ou comportamento.
\end{abstract}

PALAVRAS-CHAVE: Linguística Sistêmico-Funcional. Gênero. Estória.

RESUMEN: Esta investigación tiene como foco el funcionamiento del lenguaje en instanciaciones de géneros de la familia de las historias, de acuerdo con la perspectiva sistémico-funcional (MARTIN; ROSE, 2008; ROSE; MARTIN, 2012) que se basa en los principios de la Gramática Sistémico-Funcional (HALLIDAY; MATTHIESSEN, 2004, 2014). Para demostrar cómo funciones léxico-gramaticales y semántico-discursivas evidencian la instanciación de géneros, se analizaron y compararon tres textos que

\footnotetext{
${ }^{1}$ Este artigo é parte dos resultados das atividades de pesquisa e extensão vinculadas aos projetos "Leitura e escrita em língua portuguesa na perspectiva sistêmico-funcional" (GAP/CAL 037375) e “Ateliê de Textos" (GAP/CAL 040190), com apoio PIBIC CNPq, PROLICEN, FIEX e PROEXT MEC-Sesu.

* Professora Associada do Departamento de Letras Vernáculas e do Programa de Pós-Graduaça em Letras da Universidade Federal de Santa Maria (UFSM). Coordenadora dos projetos de pesquisa e extensão que deram origem a este artigo. E-mail:crisfuzerufsm@gmail.com

** Mestranda em Letras pela Universidade Federalde SantaMaria (UFSM). E-mail:sabrinegweber@gmail.com.
} 
comparten el objetivo de involucrar lectores/oyentes: los clásicos Caperucita Roja en las versiones de Charles Perrault, del siglo XVIII, de los Grimmm, del siglo XX, y una versión recreada de esa historia en contexto escolar en 2012. El análisis de los sistemas de transitividad y valoración, que contribuyen para la realización de las etapas de género en cada texto, destacó dos instanciaciones del género narrativa, cuyo propósito es resolver una complicación, y una instanciación del género exemplum, cuyo propósito es juzgar carácter o comportamiento.

PALABRAS-CLAVE: Lingüística Sistémico-Funcional. Género. Historia.

ABSTRACT: This paper focuses on the language functioning in instantiations of family story genres, according to the systemic functional approach of genre (MARTIN; ROSE, 2008; ROSE; MARTIN, 2012), which is based on principles of the Systemic Functional Grammar (HALLIDAY; MATTHIESSEN, 2004, 2014). To demonstrate how lexicogrammar and semantic-discursive functions emphasize the instantiation of genres, three texts that share the purpose of involving readers/listeners were analyzed and compared: the classics Little Red Riding Hood, in Charles Perrault's version, in the seventeenth century, and Grimm's, in the twentieth century, and a reinvented version of this story in a school context in 2012. The analysis of the transitivity and appraisal systems, which contribute to perform the genre stages in each text, highlighted two instantiations of the narrative genre, whose purpose is to solve a complication, and an instantiation of the exemplum genre, whose purpose is to judge character or behavior. KEYWORDS: Systemic Functional Linguistics. Genre. Story.

\section{INTRODUÇ̃̃O}

Tendo ou não o hábito de registrar criações ficcionais, em formatos como livros, contar estórias ${ }^{2}$ é, conforme Huston (2010), parte indissociável da existência humana. Nessa mesma direção, Martin e Rose (2008) reconhecem que as estórias compartilham um propósito central em todas as culturas, presente em quase todas situações e estágios de vida imagináveis. Contar uma estória que começa com uma complicação e termina com uma resolução é uma das formas mais comuns e antigas de se contar e recontar experiências próprias ou alheias. Em uma série de pesquisas sobre textos produzidos por crianças no início da escolarização, Martin e seu grupo de pesquisadores identificaram outros gêneros, além da narrativa, que são frequentemente usados pelas crianças: relato, observação, episódio, exemplum (MARTIN, 1984; MARTIN; ROSE, 2008).

Dentre as estórias que atravessam séculos e são compartilhadas por diferentes gerações, estão os contos de fada, que têm permanência no mundo contemporâneo em virtude do legado cultural representado. Conforme Merege (2010), não são neutros nem atemporais, como a indústria cultural, muitas vezes, faz crer; mas servem, não raras vezes, para transmitir valores, como demonstram os estudos de Rothery e Stenglin (1997), de Fuzer, Gerhardt e Weber (2016), dentre outros.

Como são, em nossa cultura, reinvenções de estórias que circulam com frequência no contexto escolar, principalmente em livros didáticos, tem-se verificado a necessidade de estudos detalhados de aspectos linguísticos desses textos. Estudos prévios sobre contos de fadas e reinvenções (TAVARES; SILVA, 2013; MARTINS, 2014; HERBSTER; TAVARES, 2014, dentre outros) salientam a intertextualidade do clássico Chapeuzinho Vermelho em versões produzidas em diversas épocas, como La Petit Chaperon Rouge, de Perrault, no final do século XVII; Rotkäppchen, dos Irmãos Grimm no início do século XIX; Chapeuzinho Vermelho, de Walt Disney em 193633 Fita Verde no Cabelo, de Guimarães Rosa em 1964; Chapeuzinho Amarelo, de Chico Buarque em 1979. Os trabalhos evidenciam pontos de contato entre as versões, bem como de distanciamento.

Novas versões não param de surgir: mais recentemente, Deu a louca na Chapeuzinho, animação dirigida por Cory Edwards em 2005; Chapeuzinhos Coloridos, de José Roberto Torero e Marcus Aurelius Pimenta em 2010. Esse clássico da literatura infantojuvenil

\footnotetext{
${ }^{2}$ Utiliza-se, aqui, o termo "estórias" à semelhança de stories, que se referem aos gêneros cujo propósito é envolver o leitor com fatos e acontecimentos geralmente ficcionais. Esse termo é usado em distinção a "histórias" (histories), que se referem aos gêneros cujo propósito é relatar fatos e acontecimentos não ficcionais (MARTIN; ROSE, 2008).

${ }^{3}$ Os estúdios de Walt Disney difundiram a adaptação da versão dos Irmãos Grimm para o púbico infantil na primeira metade do século XX. Provavelmente por isso essa versão de Chapeuzinho Vermelho seja a mais popular até hoje.
} 
também está entre os preferidos de estudantes dos anos finais do ensino fundamental que têm participado, desde 2011, do projeto de ensino e extensão Ateliê de Textos ${ }^{4}$, que promove oficinas de leitura e produção textual e publica coletâneas de estórias produzidas pelos alunos das escolas públicas que participam do projeto. Em uma dessas coletâneas, está publicado Chapeuzinho dos olhos vermelhos, um dos textos analisados neste estudo.

A análise que aqui se propõe está ancorada na perspectiva de gênero desenvolvida pela Linguística Sistêmico-Funcional, a partir dos trabalhos do grupo de pesquisadores coordenado por Martin, desde 1983, na Austrália (MARTIN, 1984). Nessa perspectiva, o gênero é cenário apropriado para o estudo contextualizado da gramática da língua, o que justifica seu potencial para aplicações pedagógicas.

No Brasil, pesquisadores do grupo Sistêmica Através das Línguas (SAL), coordenado por Leila Barbara, têm investigado instanciações de gêneros na perspectiva da Linguística Sistêmico-Funcional ${ }^{5}$. A título de exemplo, destacam-se os estudos de Farencena (2015) sobre o gênero exposição de ponto de vista em artigos de opinião; de Gehrke (2015) sobre o gênero observação comentada em microcrônicas verbo-visuais; de Santos (2016) sobre gêneros da família dos relatórios em livros didáticos de Ciências Naturais; de Fuzer, Gerhardt e Weber (2016) sobre o gênero narrativa em uma das versões de O Pequeno Polegar; bem como de Fuzer (2017) sobre realizações linguísticas e instanciação de gêneros em textos fabulísticos. Somando-se a esses estudos, o presente trabalho busca ampliar a investigação sobre aspectos léxico-gramaticais e semântico-discursivos que contribuem na organização das etapas de gênero e realização do propósito comunicativo. O estudo objetiva investigar quais gêneros da família das estórias estão instanciados em Chapeuzinho Vermelho considerando três contextos de produção: a versão de Charles Perrault, na França do século XVII, a dos Irmãos Grimm, na Alemanha do século XX e a produzida em contexto escolar por uma estudante do $7^{\circ}$ ano do ensino fundamental em 2012, no Brasil. A análise focaliza realizações linguísticas do sistema de avaliatividade, com base em Martin e White (2005) e do sistema de transitividade, com base em Halliday e Matthiessen (2004, 2014).

Este trabalho se desenvolve em três seções que apresentam, sucessivamente, pressupostos teóricos da Linguística SistêmicoFuncional, com ênfase nos sistemas de transitividade e avaliatividade; a metodologia e os resultados das análises dos textos selecionados e, por fim, algumas considerações sobre os desdobramentos do estudo aqui iniciado.

\section{A PERSPECTIVA SISTÊMICO-FUNCIONAL DE GÊNERO}

Este estudo tem como eixo teórico-metodológico a Linguística Sistêmico-Funcional (LSF), que tem como base a Gramática Sistêmico-Funcional (GSF), de Halliday $(1985,1994)$ e Halliday e Matthiessen $(2004,2014)$. Por ser um aparato teóricometodológico cujo objetivo é analisar a linguagem em funcionamento na sociedade, a GSF considera que todo uso linguístico é pautado por escolhas feitas pelo falante dentre uma gama de possibilidades que a língua disponibiliza como uma rede de sistemas, organizados em estratos: o léxico-gramatical realiza o semântico, que, por sua vez, realiza o contexto (HALLIDAY; MATTHIESSEN, 2014). No estrato semântico, a linguagem desempenha as metafunções ideacional, interpessoal e textual, que se realizam, respectivamente, pelos sistemas léxico-gramaticais de transitividade, modo e estrutura temática.

Na transitividade, sistema focalizado neste estudo, a oração tem como núcleo experiencial o processo, que pode ser de diferentes tipos (relacional, verbal, mental, comportamental, material ou existencial) e envolver participantes e, eventualmente, circunstâncias. Cada tipo de oração representa determinadas experiências humanas instanciadas ${ }^{6}$ em textos, que se inserem em contextos específicos (HALLIDAY; MATTHIESSEN, 2014).

\footnotetext{
${ }^{4}$ Projeto registrado sob o número 029622 no Gabinete de Projetos do Centro de Artes e Letras da UFSM, coordenado pela primeira autora deste artigo desde sua criação e do qual a segunda autora participou como ministrante de oficinas durante três anos. Mais informações sobre o projeto em: $<$ www.ufsm.br/ateliedetextos $>$.

${ }^{5}$ Essa abordagem também tem sido referida como Escola de Sydney (Hyon, 1997) ou Escola Sistêmico-Funcional de Sydney (MOTTA-ROTH; HEBERLE, 2015).

${ }^{6}$ Instanciação, de modo geral, é a relação entre um potencial (o sistema linguístico) e sua instância (o texto) (HALLIDAY, 2009; HALLIDAY; MATTHIESSEN, 2014). Nessa perspectiva, o gênero instancia o contexto de cultura (MARTIN, 1984).
} 
O contexto, conforme Halliday e Hasan (1989), pode ser descrito a partir da situação e da cultura em que o texto se insere. O contexto de situação pode ser descrito a partir de três variáveis: campo, relações e modo. O campo diz respeito a aspectos como conteúdo, objetivo, meio e lugar de circulação do texto; as relações implicam os papéis sociais dos participantes no texto e na interação (THOMPSON; THETELA, 1995); o modo diz respeito aos elementos linguísticos como um todo estruturante do texto. O contexto de cultura associa-se a práticas mais amplas em determinados ambientes socioculturais, incluindo convenções sociais. Ao contexto de cultura Martin (1992) associa a noção de gênero, definido como um "processo social organizado por etapas e orientados para propósitos sociais"7 (MARTIN, 1984, p. 9; MARTIN; ROSE, 2008, p. 8). A constituição em etapas deve-se ao fato de que, conforme os autores, é preciso mais de um passo para se alcançar o propósito sociocomunicativo do gênero; tal processo é social porque os escritores moldam seus textos para leitores específicos, integrando situação e cultura.

Após uma série de pesquisas sobre gêneros instanciados em textos escolares, o grupo de sistemicistas australianos concluiu que existe uma grande família de gêneros tripartida de acordo com os propósitos: envolver, avaliar e informar (ROSE; MARTIN, 2012, p.128). Para cada propósito geral, existem famílias, que, por sua vez, alojam os gêneros que se distinguem por propósitos mais específicos. Da família das estórias, por exemplo, fazem parte seis gêneros encontrados em textos produzidos em escolas australianas: o relato, a observação, a narrativa, o exemplum, o episódio e a notícia (MARTIN; ROSE, 2008; ROSE; MARTIN, 2012). Cada gênero é textualizado em etapas, que são componentes relativamente estáveis de sua organização, e em fases, que são componentes variáveis e podem constituir diferentes etapas (MARTIN; ROSE, 2008).

Nessa perspectiva, a narrativa é o gênero que tem o propósito de resolver uma complicação. A complicação e a resolução são as etapas que, conforme Martin e Rose (2008, p. 82), definem esse gênero. Os autores tomaram como base o modelo de Labov e Waletzky (1967), segundo os quais a estrutura da narrativa é formada por orações que se ligam a eventos temporais do discurso relatado pelos indivíduos que contam a história (RODRIGUES, 2010).

Outro gênero da família das estórias é o exemplum, que tem por objetivo julgar o caráter ou o comportamento de um ou mais participantes (MARTIN; ROSE, 2008, p. 51). A estrutura esquemática do gênero exemplum constitui-se das etapas Incidente, em que se apresenta uma interrupção dos acontecimentos ou das atividades habituais das personagens reveladas na etapa Orientação, e Interpretação, que projeta para trás os eventos anteriores, avaliando o comportamento do(s) participante(s) (MARTIN; ROSE, 2008, p. 62). No exemplum, portanto, diferente da narrativa, não é apresentada resolução para o problema indicado na etapa Incidente. $\mathrm{O}$ caráter moralizante é indicado na etapa Interpretação, em que se condena ou elogia o comportamento de um ou mais participantes do texto (MARTIN; ROSE, 2008).

A identificação do propósito sociocomunicativo e da estrutura esquemática do gênero é possibilitada pela análise linguística dos textos, uma vez que recorrências léxico-gramaticais e semântico-discursivas realizam o contexto que, por sua vez, instancia-se nos textos. Os campos semânticos do subsistema atitude do sistema de avaliatividade (MARTIN; WHITE, 2005) são critérios úteis para identificação do propósito específico das estórias, fornecendo evidências de instanciação de gêneros distintos. Assim, instanciações de exemplum apresentam, tipicamente, ocorrências expressivas de julgamento (de estima social ou de sanção social), ao passo que episódios se caracterizam por ocorrências de afeto e observações por apreciação. Narrativas apresentam diversificados usos de avaliações de atitude, e relatos apresentam incidência menos expressiva de avaliações (MARTIN; ROSE 2008). Com base nesses princípios teóricos, são organizadas as diretrizes metodológicas para análise, descritas na seção a seguir.

\section{DIRETRIZES METODOLÓGICAS E ANÁLISE DE INSTANCIAÇÕES DE GÊNERO DA FAMÍLIA DAS ESTÓRIAS}

Para descrever a instanciação de gênero da família das estórias na perspectiva sistêmico-funcional, selecionou-se o clássico Chapeuzinho Vermelho, de Charles Perrault (traduzido em língua portuguesa por Maria Stela Gonçalves), autor da primeira versão

${ }^{7}$ Tradução nossa de: "We define a genre as a staged purposeful social process - genre, in other words, are goal oriented, and work towards these goals in steps" (MARTIN, 1984, p.9). 
escrita do conto, no século XVII, na França. Para uma análise comparativa, foi selecionada a versão pelos Irmãos Grimm, na Alemanha do século XIX (traduzida em língua portuguesa, em 2010, por Nilce Teixeira.

Além disso, para acrescentar à análise uma versão produzida em contexto contemporâneo, foi selecionado Chapeuzinho dos Olhos Vermelhos, publicado na coletânea Modernizando os Clássicos, em 2012, que reúne versões de contos de fada reinventadas por alunos dos anos finais do ensino fundamental de escolas públicas que participaram do projeto de ensino e extensão Ateliê de Textos.

Para a análise dos textos, adotaram-se os seguintes procedimentos: a) descrição das variáveis de contexto situacional (campo, relações e modo) de cada texto; b) identificação e análise das etapas do gênero com base no conteúdo e nas marcas linguísticas cujas funções semântico-discursivas do sistema de avaliatividade e funções léxico-gramaticais dos sistemas de transitividade e modalidade servem de evidências; c) comparação entre os dados analisados e organização das semelhanças e diferenças encontradas; d) sistematização de aspectos caracterizadores do gênero instanciado em cada texto analisado.

A descrição das variáveis do contexto de situação mostra algumas diferenças entre os textos, que são decorrentes da época e da sociedade em que o texto foi produzido. Tais descrições são apresentadas no início de cada subseção dos resultados das análises de Chapeuzinho Vermelho, de Charles Perrault, Chapeuzinho Vermelho, dos Irmãos Grimm e Chapeuzinho dos Olhos Vermelhos, de Rosceli Castro. Na sequência, para revelar o(s) gênero(s) instanciado(s) nos textos, são apresentados recursos linguísticos que evidenciam o propósito sociocomunicativo e as etapas de gênero.

\subsection{INSTANCIAÇÃO DE EXEMPLUM NA VERSÃO DE PERRAULT}

O contexto social em que Chapeuzinho Vermelho, na versão de Charles Perrault, foi produzido envolve a França do século XVII. Para a sociedade francesa da época, contar ou recontar estórias para as crianças era uma maneira de ensinar bons modos aos filhos, em especial para as meninas (CANTON, 2009).

Com relação ao contexto de situação, o texto se configura, no que se refere à variável campo, como um alerta aos ouvintes/leitores sobre as consequências para quem é desobediente - no caso, Chapeuzinho, depois de desobedecer aos conselhos da mãe, é morta pelo lobo ao final da estória. O papel de uma menina como vítima de um desconhecido ilustra uma situação específica para servir de exemplo acerca do comportamento considerado inadequado.

Na variável relações, os participantes do texto são um narrador observador que reproduz falas das personagens à medida que os eventos são apresentados. No final, ao explicitar a moral, insere sua voz por meio de dêiticos, como em "Vê-se aqui" e "Digo". A relação entre a mãe e a menina é desigual, pois, na troca de bens e serviços, a mãe comanda - "Vai ver" e "leva-lhe" -, e a menina realiza o serviço solicitado. A relação entre o lobo e a menina também é desigual nos dois momentos em que eles se encontram. No primeiro momento, a menina detém informações que são solicitadas pelo lobo. No segundo momento, o lobo disfarçado de avó exerce poder sobre a menina ao dirigir-lhe comandos - "puxa a cavilha", "põe o bolo folhado e o potinho de manteiga na caixa de mantimentos e vem deitar-se comigo". Assim como obedeceu ao comando da mãe, a menina obedece aos comandos do lobo. Na sequência, os papéis na troca de informações se invertem: a menina solicita informações dirigindo uma série de perguntas, a que o lobo responde, até o momento em que o diálogo termina com o ataque do lobo. Na moral, o narrador coloca-se em posição de superioridade em relação aos ouvintes/leitores, ao fornecer informações sobre o perfil dos homens mal-intencionados representados como lobos na estória. O narrador também realiza o papel de conselheiro de crianças e donzelas, ao julgar negativamente seu comportamento - "Fazem muito mal em escutar qualquer tipo de gente" - e ao alertar sobre as consequências desse comportamento - "Mas ai de quem desconhece que esses lobos adocicados".

Embora originalmente de cunho popular e oral, Chapeuzinho Vermelho, junto de outras estórias, foi recolhida e registrada por escrito no livro conhecido como Contos da Mamãe Gansa entre 1691 e 1697. A tradução em português usada neste trabalho pode ser encontrada em formatos impresso e on-line. 
A análise de ocorrências dos sistemas de transitividade em associação com o sistema de avaliatividade evidencia as etapas do gênero instanciado nessa versão de Perrault. A etapa de Orientação inicia com uma oração existencial, em que é apresentada uma das personagens, destacada no excerto 1 :

(1) Era uma vez uma menininha de aldeia, a mais bonita que já se vira; sua mãe a adorava, e sua avó mais ainda.

O existente "uma menininha de aldeia" indica a origem da personagem, que é avaliada por meio de apreciação positiva ("a mais bonita que já se vira"). Ainda na etapa Orientação, outra participante é introduzida como Dizente por meio de processo verbal de semiose $^{8}$, como se verifica no excerto 2.

(2) Certo dia, tendo cozinhado e feito bolos folhados, sua mãe lhe diz

- Vai ver como está passando tua avó, pois ela me disse que estava doente; leva-lhe um bolo folhado e este pequeno pote de manteiga.

Chapeuzinho Vermelho saiu imediatamente para ir à casa da avó, que morava em outra aldeia.

Embora a natureza do processo "dizer" seja neutra, na Citação que representa a fala da personagem aparecem dois comandos direcionados à Chapeuzinho Vermelho: "Vai ver" e "leva-lhe”. A reação da menina, diante da solicitação da mãe, é imediatamente realizar o comando, representada pelas orações materiais "saiu imediatamente para ir à casa da avó", o que indica uma relação de poder entre as personagens.

Na sequência, um novo participante, o lobo, é inserido no texto, o que promove uma interrupção na sequência que seria habitual a uma menina que vai visitar a avó.

(3) [...] Passando por um bosque, encontrou o compadre lobo, que tinha muita vontade de comê-la; mas não ousou fazê-lo por causa de alguns lenhadores que estavam na floresta. Ele lhe perguntou aonde ia [...].

Em (3), a introdução do "compadre lobo" na estória se dá pela função de Escopo-entidade do processo material "encontrou”, e o papel desse personagem na etapa Incidente é indicado pela função de Portador da oração atributiva possessiva "tinha muita vontade de comê-la", que revele a intenção do lobo em relação à menina. Como Experienciador em "não ousou fazê-lo" e Dizente em "Ihe perguntou aonde ia”, o lobo é representado como perspicaz: em vez de satisfazer a sua vontade naquele momento e correr risco de vida (haja vista a circunstância "por causa de alguns lenhadores que estavam na floresta"), dialoga com a menina para descobrir o local para onde ela se dirige e lá realizar seu intento.

Chapeuzinho, por sua vez, é representada como uma menina ingênua, pois dialoga com o lobo e responde a todas as questões feitas por ele, dando-lhe detalhes de como chegar à casa da avó.

(4) Ele lhe perguntou aonde ia; a pobre criança, que não sabia que é perigoso deter-se para escutar um lobo, lhe disse:

- Vou ver minha avó e levar-lhe um bolo folhado com um potinho de manteiga que minha mãe está lhe enviando.

- Tua avó mora muito longe? - pergunta-lhe o Lobo.

- Oh! Sim - diz Chapeuzinho Vermelho - é para lá do moinho que vedes bem lá embaixo, lá embaixo, na primeira casa da aldeia.

A ingenuidade da menina, em (4), é indicada pela marca de apreciação "pobre" e pela sua participação como Experienciador do processo mental com polaridade negativa "não sabia", cujo Fenômeno, na forma de oração relacional, apresenta uma apreciação negativa para essa atitude - "é perigoso".

${ }^{8}$ Esse tipo de processo verbal pode se apresentar em três subtipos: neutro, de indicação e de comando (HALLIDAY; MATTHIESSEN, 2014, p. 305).

Fuzer \& Weber|Chapeuzinho Vermelho em três versóes: análise de gênero na perspectiva sistêmico-funcional 
Ainda na etapa Incidente, há uma série de eventos realizados pelo Lobo e pela Chapeuzinho, os quais são apresentados por meio de orações materiais, como se verifica em (5).

(5) O Lobo começou a correr com todas forças pelo caminho que era mais curto, enquanto a menininha foi pelo caminho mais longo, divertindo-se em colher avelãs, em correr atrás das borboletas e em fazer ramalhetes com as pequenas flores que encontrava.

O comportamento do lobo ("correr com todas as forças") o representa como ágil e esperto, em contraste com o comportamento da menina ("foi", "divertindo-se"), cuja lentidão é indicada também pelos processos materiais que executa ao longo do caminho ("colher avelãs", "correr atrás das borboletas", "fazer ramalhetes"). O caminho mais longo associado às ações que distraem Chapeuzinho fornecem ao lobo tempo suficiente para executar o seu plano. Na casa, após devorar a avó, aguarda pela chegada da menina, que não reconhece a voz do lobo escondido sob as cobertas na cama da avó e atende à proposta que lhe é feita:

\section{(5) - Põe o bolo folhado e o potinho de manteiga na caixa de mantimentos e vem deitar-se comigo.}

Chapeuzinho Vermelho se despe e vai pôr-se no leito, onde fica bastante espantada ao ver como era o corpo de sua avó sem roupas.

Em (5), a proposta é realizada léxico-gramaticalmente por comandos explícitos, no modo oracional imperativo ("Põe" e "vem deitarse"). A reação da menina é não verbal; as orações materiais indicam não só a obediência ao comando ("vai pôr-se no leito"), mas também, implicitamente, uma alusão à temática da sexualidade ("se despe"). O Atributo "espantada" realiza uma avaliação de afeto, intensificada por "bastante", indicando a reação emocional da menina ao experienciar a percepção da nudez, representada pela oração mental perceptiva "ao ver como era o corpo da sua avó sem roupas". A partir disso, inicia-se a sequência de perguntas por Chapeuzinho e respostas pelo lobo.

(6) - Minha avó, por que tendes braços tão grandes?

- É para melhor te abraçar, minha filha. [...]

- Minha avó, por tendes dentes tão grandes?

- É para te comer.

E, ao dizer estas palavras, o malévolo lobo se lançou sobre Chapeuzinho Vermelho e a comeu.

Nas falas do Lobo, Chapeuzinho, referida pelo pronome "te", é representada como Meta ou Fenômenos de processos de que o lobo é o agente. O problema principal da etapa Incidente, entretanto, é explicitado na última fala do lobo "te comer", seguida da execução "se lançou sobre Chapeuzinho e a comeu". A ambiguidade lexical presente nessas orações encerra a etapa Incidente e dá o gancho para a etapa Intepretação, em que o comportamento de crianças e jovens donzelas é avaliado:

(7) Moral: Vê-se aqui que crianças pequenas,

Sobretudo meninas pequenas,

Bonitas, de belas formas e gentis,

Fazem muito mal em escutar qualquer tipo de gente,

O que não é algo raro,

Tanto é assim que o lobo as come. [...]

Mas ai de quem desconhece que esses lobos adocicados,

De todos os lobos são os mais perigosos.

A expressão "fazem muito mal" indica um julgamento negativo em relação ao comportamento das meninas que escutam "qualquer tipo de gente" e se deixam levar pelos "lobos adocicados", avaliados por meio da apreciação negativa "os mais perigosos". A expressão "ai de quem desconhece" reforça o julgamento negativo e alerta sobre o destino dessas meninas desprevenidas. Dessa forma, verificase a instanciação do propósito do gênero exemplum: compartilhar julgamentos de comportamento (nesse caso, a ingenuidade e imprudência de Chapeuzinho Vermelho) e de caráter (a falsidade do lobo). 


\subsection{INSTANCIAÇÃO DE NARRATIVA NA VERSÃO DOS IRMÃOS GRIMM}

Cerca de um século depois da publicação francesa, uma versão de Chapeuzinho Vermelho é publicada em alemão pelos Irmãos Grimm em Contos de Fadas para o Lar e as Crianças (em alemão: Kinder-und Hausmärchen), em 1812.

Jacob Grimm (1785) e Wilhelm Grimm (1786) recolheram estórias populares que escutavam de camponeses alemães e liam em manuscritos antigos. "Estudiosos e letrados, os Grimm procederam a um complexo trabalho de depuração dos textos, que não apenas os adequou ao público-alvo do espaço doméstico da classe média burguesa, como também lapidou seu caráter estético, potencializando assim seu efeito artístico" (VOLOBUEF, 2013).

De acordo com Canton (2009), as estórias, a partir dos Irmãos Grimm, passaram a ser destinadas às crianças. A criança, vista como um ser fraco, ingênuo e inocente, deveria ser educada, protegida e preservada de certos tipos de experiências - como a sexualidade. A criança também deveria ser disciplinada e bondosa para, assim, ser recompensada; se fosse desobediente deveria ser punida. Além disso, deveria cultivar os bons hábitos, as virtudes e a razão (CANTON, 2009). Foi, pois, a partir dos Irmãos Grimm, que o conto de fadas assumiu sua "roupagem" atual.

As etapas que orientam e relatam problemas em que a protagonista se envolve são muito semelhantes nas versões de Perrault e dos Irmãos Grimm. A diferença principal está no acréscimo de uma etapa, na versão dos Grimm, que não existe na versão de Perrault a Resolução -, como se verá nas análises que seguem.

Na versão dos Irmãos Grimm, a etapa de Orientação é constituída apenas pela fase cenário, em que as personagens são caracterizadas, como se verifica no excerto (8):

(8) Era uma vez uma menininha encantadora. [...] Certa ocasião ganhou dela um pequeno capuz de veludo vermelho. Assentava-lhe tão bem que a menina queria usá-lo o tempo todo, e por isso passou a ser chamada Chapeuzinho Vermelho.

Um dia, a mãe da menina lhe disse: "Chapeuzinho Vermelho, aqui estão alguns bolinhos e uma garrafa de vinho. Leve-os para sua avó. Ela está doente, sentindo-se fraquinha, e estas coisas vão revigorá-la.

Nesse excerto, a identidade da personagem que será protagonista é construída, na voz do narrador, por meio do epíteto "encantadora”, que expressa apreciação positiva, e da oração "passou a ser chamada Chapeuzinho Vermelho", que informa o apelido da personagem em razão da apreciação positiva (“Assentava-lhe tão bem”) atribuída ao capuz com que a avó a presenteou. A avó é caracterizada, na voz de outra personagem (a mãe de Chapeuzinho Vermelho), pelos Atributos “doente” e "fraquinha”. É comum nos contos de fadas, conforme Soares (2010, p.7), alguns personagens não terem nomes próprios e aparecerem apenas como título ou características que possuem ou a profissão que exercem.

Ainda na etapa Orientação, é apresentado o cenário onde se encontram as personagens:

(9) Sua avó morava lá no meio da mata, a mais ou menos uma hora de caminhada da aldeia.

As circunstâncias de localização "lá no meio da mata" e "da aldeia” remetem a lugares imprecisos, sem nomeações próprias, aspectos típicos de contos de fada. A distância entre os dois lugares é indicada não em unidade de espaço, mas de tempo, expressa, também de modo pouco preciso, pela circunstância de duração "a mais ou menos uma hora de caminhada”. Além de identidades e localização, são apresentadas, no cenário, atividades, as quais são indicadas na voz da mãe, que faz uma série de recomendações à filha:

(10) Um dia, a mãe da menina lhe disse: "Chapeuzinho Vermelho, aqui estão alguns bolinhos e uma garrafa de vinho. Leve-os para sua avó. Ela está doente, sentindo-se fraquinha, e estas coisas vão revigorá-la. Trate de sair agora mesmo, antes que o sol fique quente, e quando estiver na floresta olhe para frente como uma boa menina e não se desvie do caminho. Senão, pode cair e quebrar a garrafa, e não sobrará nada para a avó. E quando entrar, 
não se esqueça de dizer bom dia e não fique bisbilhotando pelos cantos da casa". "Farei tudo que está dizendo", Chapeuzinho Vermelho prometeu à mãe.

A fala da mãe é introduzida, assim como na versão de Perrault, por processo verbal de natureza neutra ("disse"), mas a resposta de Chapeuzinho é indicada por processo verbal performativo ("prometeu”). Os comandos são explicitados no modo oracional imperativo, que demandam da menina uma série de ações (levar coisas para a avó, sair antes que o sol fique quente, olhar para frente, não se desviar do caminho, dizer bom dia, não ficar bisbilhotando) e que representam comportamentos considerados adequados a "uma boa menina". Chapeuzinho, em sua fala, demonstra reagir positivamente aos conselhos da mãe, prometendo segui-los ("Farei tudo que está dizendo"), o que a representa como uma filha obediente.

Um dos conselhos da mãe é atendido logo que Chapeuzinho pisa na floresta: dizer "bom dia", em (11), que, por sua vez, indica o atendimento da menina a um dos conselhos dados pela mãe em (10) ("não se esqueça de dizer bom dia").

(11) Mal pisara na floresta, Chapeuzinho Vermelho topou com o lobo. Como não tinha a menor ideia do animal malvado que ele era, não teve um pingo de medo.

"Bom dia, Chapeuzinho Vermelho", disse o lobo.

"Bom dia, senhor lobo", ela respondeu. [...]

O uso do artigo definido em "o lobo" em sua primeira menção no texto sinaliza que ele não era um desconhecido. A menina desconhecia, porém, suas intenções, como indica a oração "não tinha a menor ideia", realizando uma figura mental cognitiva com polaridade negativa que indica ingenuidade. Em decorrência disso, sua reação é de afeto, indicada pela oração mental emotiva "não teve um pingo de medo" e pela Verbiagem "Bom dia, senhor lobo".

Assim como ocorre na versão de Perrault, devido à sua ingenuidade, a menina responde às perguntas do lobo, revelando o lugar para onde estava indo. Dessa forma, inicia-se a etapa Complicação da estória, que se desdobra em várias fases, uma das quais é a reflexão, realizada em (12) e (13).

(12) O lobo pensou com seus botões: "Esta coisinha nova e tenra vai dar um petisco e tanto! Vai ser ainda mais suculenta que a velha. Se tu fores realmente matreiro, vais capturar as duas."

A reflexão do lobo, introduzida pelo processo mental "pensou”, revela suas intenções e o planejamento da ação seguinte, criando expectativas no leitor/ouvinte. O Fenômeno pensando é constituído por uma série de orações relacionais em que os Atributos expressam apreciações em relação à menina ("coisinha nova e tenra", "um petisco e tanto") e em relação à avó ("suculenta”) e, também, julgamento em relação ao próprio lobo ("matreiro"). A oração material "vais capturar as duas" explicita o plano do lobo e antecipa para o leitor o que poderá acontecer na sequência da estória.

A fase reflexão também ocorre envolvendo Chapeuzinho, como indica a oração mental cognitiva introduzida por “pensou” em (13).

(13) Chapeuzinho Vermelho abriu bem os olhos e notou como os raios de sol dançavam nas árvores. Viu flores bonitas por todos os cantos e pensou: "Se eu levar um buquê fresquinho, a vovó ficará radiante. Ainda é cedo, tenho tempo de sobra para chegar lá, com certeza."

As orações relacionais cujos Atributos indicam avaliação de afeto em relação à avó ("radiante") e apreciação em relação ao tempo disponível por Chapeuzinho ("cedo", "tempo de sobra”) representam uma justificativa para as ações que se seguirão, acarretando a demora em chegar à casa da avó.

É importante destacar que a variedade de ocorrências de atitude que se verificou até aqui, sem que um tipo predomine, denota a natureza do gênero narrativa quanto à avaliatividade, como já haviam constatado Martin e Rose (2008) em suas pesquisas. 
Na sequência da Complicação, as ações de Chapeuzinho na floresta denotam desobediência a um dos conselhos dados pela mãe, como indicam as orações materiais destacadas em (14).

(14) Chapeuzinho Vermelho deixou a trilha e correu para dentro do bosque a procura de flores. Mal colhia uma aqui, avistava outra ainda mais bonita acolá, e ia atrás dela. Assim, foi se embrenhando cada vez mais na mata.

A Complicação chega ao ápice quando o lobo devora a avó e, na sequência, a menina, assim como ocorre na versão de Perrault. Como foi dito anteriormente, as duas primeiras etapas são muito semelhantes nas versões de Perrault e dos Irmãos Grimm. A diferença fundamental que indica a mudança do propósito da estória é a etapa Resolução, que não existe na versão de Perrault. $O$ acréscimo dessa etapa muda a perspectiva da estória e, por conseguinte, a mensagem moralizante.

Na etapa Resolução, na versão dos Grimm, uma nova personagem é introduzida na história para resolver a complicação:

(15) Um caçador que por acaso ia passando junto à casa pensou: "Como essa velha está roncando alto! Melhor ir ver se há algum problema”.

Entrou na casa e, ao chegar junto à cama, percebeu que havia um lobo deitado nela.

Em (15), o artigo indefinido em "um caçador" contribui para apresentar de modo impreciso a personagem, identificado apenas pela sua profissão. A circunstância "por caso" denota o aspecto fortuito dos contos de fada, em que é comum o protagonista em apuros receber a ajuda da sorte ou de um elemento mágico (TATAR, 2004). A indicação de que o caçador será a solução para o problema está na fase reflexão, novamente introduzida pelo processo mental "pensou”, que tem como parte do Fenômeno a oração mental perceptiva "ir ver se há algum problema”. A apreciação expressa por "Melhor" indica a decisão do caçador em descobrir o motivo do ronco que chamou sua atenção. Após entrar na casa e avistar o lobo deitado na cama, o caçador vivencia processos materiais e mentais que ocasionam a solução de parte do problema:

(16) [...] Sacou sua espingarda e já estava fazendo pontaria quando atinou que o lobo devia ter comido a avó e que, assim, ele ainda poderia salvá-la. Em vez de atirar, pegou uma tesoura e começou a abrir a barriga do lobo adormecido. Depois de algumas tesouradas, avistou um gorro vermelho. Mais algumas, e menina pulou fora [...]. Embora mal pudesse respirar, a idosa vovó também conseguiu sair da barriga.

Em (16), o caçador desempenha a função de Ator de uma série de orações materiais que denotam uma sequência de eventos ("sacou sua espingarda", "estava fazendo pontaria", "salvá-la", "pegou uma tesoura" e "começou a abrir a barriga"), intercaladas com a função de Experienciador de processos mentais ("atinou” e "avistou”), que o representam como a salvação de Chapeuzinho e sua avó. O efeito desses eventos é realizado pelas orações materiais "pulou para fora" e "conseguiu sair da barriga”, em que a menina e a idosa vovó são Ator, respectivamente.

A segunda parte da Resolução se dá por iniciativa da própria Chapeuzinho Vermelho:

(17) Mais que depressa, Chapeuzinho Vermelho catou umas pedras grandes e encheu a barriga do lobo com elas.

Quando acordou, o lobo tentou sair correndo, mas as pedras eram tão pesadas que suas pernas bambearam $\mathrm{e}$ ele caiu morto.

Diferentemente da versão de Perrault, em que Chapeuzinho termina como vítima do lobo (representada como Meta do processo "comer"), na versão dos Grimm os papéis se invertem: o lobo torna-se a vítima das ações, inicialmente, do caçador e, depois, de Chapeuzinho, a qual, de Meta, passa a Ator dos processos materiais ("catou umas pedras", "encheu a barriga do lobo com elas"). O castigo passa a ser vivenciado, portanto, pelo lobo. Dessa forma, evidencia-se o valor de justiça por meio do castigo físico como punição por transgressões às regras de conduta. Esse pensamento de que "o mal se paga com o mal" tem sido passado por gerações por meio dessa e de outras estórias orais imortalizadas pelos irmãos Grimm. 
A etapa de Avaliação é formada por uma fase de reação na estória:

(18) Chapeuzinho Vermelho, sua avó e o caçador ficaram radiantes. O caçador esfolou o lobo e levou a pele para casa.

O Atributo "radiantes" indica a reação emocional das personagens perante a morte do lobo. As orações materiais "esfolou o lobo" e "levou a pele para casa" representam uma espécie de recompensa ao caçador.

A estória finaliza com a etapa Coda, na qual há o retorno ao contexto inicial da narrativa organizado em duas fases: um efeito relacionado à avó e uma reflexão por parte da menina.

(19) A avó comeu os bolinhos, tomou o vinho que a neta lhe levara e recuperou a saúde. Chapeuzinho Vermelho disse consigo: "Nunca se desvie do caminho e nunca entre na mata quando sua mãe proibir".

A recuperação da saúde da avó é representada como efeito dos bolinhos e do vinho, que foram levados por Chapeuzinho e foi o motivo inicial de sua visita à vó. Dessa forma, o objetivo indicado na etapa Orientação se efetiva. Já a fase reflexão é introduzida pela figura mental cognitiva expressa na forma de oração verbal "disse consigo", da qual Chapeuzinho Vermelho é Experienciador. O retorno ao momento inicial da narrativa se verifica na referência às recomendações da mãe ("quando sua mãe proibir"), apresentadas na etapa Orientação dessa narrativa. Os comandos "nunca se desvie do caminho" e "nunca entre na mata", em polaridade negativa, sinalizam a mensagem moralizante da estória em relação ao comportamento dos filhos. Na versão dos Irmãos Grimm, Chapeuzinho teve uma segunda chance para poder repensar sobre o erro de desobedecer à mãe, diferente da mensagem explicitada pela etapa Interpretação na versão de Perrault, vista anteriormente.

\subsection{INSTANCIAÇÃO DE NARRATIVA NA VERSÃO PRODUZIDA EM CONTEXTO ESCOLAR}

O texto Chapeuzinho dos Olhos Vermelhos foi produzido por uma aluna do $6^{\circ}$ ano do ensino fundamental durante uma oficina de leitura e produção textual realizada no âmbito do projeto de extensão Ateliê de Textos (GAP/CAL/UFSM 029622), em Santa Maria, RS. Após reescrito e revisado pela aluna com o auxílio da mediadora da oficina, o texto foi publicado, na coletânea "Modernizando os Clássicos", junto de outros textos produzidos por alunos participantes da mesma edição do projeto.

Assim como a versão dos irmãos Grimm, no qual a aluna se inspirou, Chapeuzinho dos olhos vermelhos instancia o gênero narrativa, com as etapas Orientação, Complicação, Avaliação, Resolução e Coda. Nessa versão, fazem-se presentes tecnologias de comunicação (computador, internet, game portátil, televisão) e transporte (helicóptero) como marcas da sociedade contemporânea.

A etapa Orientação inicia com a fase comentário, por meio do qual o narrador marca sua presença na construção da narrativa:

(20) Era uma vez... Não! Chega de "era uma vez". Vamos inovar!".

A expressão "Não! Chega de" indica um julgamento com relação à forma padrão de iniciar contos de fada como um acontecimento distante no passado. A inovação, anunciada na oração "Vamos inovar!", está na aproximação temporal dos eventos ao contexto social em que se encontram autora e leitores, indicada pela circunstância "Há uns dias atrás” na fase cenário:

(21) Há uns dias atrás, uma menina chamada Ana vivia com sua mãe em uma cidade pacata chamada Rio Bonito.

O cenário, assim como nos textos analisados nas seções anteriores, apresenta identidades, atividades e localização. Porém, diferente dos outros textos, não se verifica uma imprecisão espacial na recontextualização produzida pela aluna, já que um nome supostamente real é dado à personagem (“Ana”) e ao lugar onde vive ("Rio Bonito").

(22) Um dia, sua mãe obrigou-a a sair de casa para ela conhecer o mundo fora de quatro paredes e longe da tela do computador e também para levar remédios para sua avó que estava doente: 
- Ana, saia já desse quarto! Faz um dia lindo lá fora! Aproveite para visitar sua avó e levar esses remédios para ela.

No cenário, também são representadas atividades atribuídas à menina, inicialmente, na voz do narrador e, na sequência, reiteradas pela voz da mãe. Nessa versão, as atividades de sair do quarto e ficar longe da tela do computador são apresentadas em primeiro plano, contribuindo para representação de uma adolescente típica em uma sociedade ávida por tecnologia. O processo "aproveite", na fala da mãe, coloca em segundo plano as atividades em benefício da avó. Em vez de bolo e vinho, a menina leva remédios para a avó, o que também contribui para caracterizar costumes da sociedade contemporânea quanto ao uso de substâncias químicas para tratamento de problemas de saúde.

Ao contrário das versões de Perrault e Grimm, a reação da menina perante o comando da mãe não é de aceite imediato.

(23) -Aah, mãe. Deixa eu ficar mais um pouco no "pc", ainda nem terminei de ver um dos episódios daquele anime. E para que tantos remédios?

- Como pode dizer isso? Ela está com uma crise grave de síndrome do pânico! E além do mais, você fica muito tempo no computador.

Chapeuzinho ficou vermelha de raiva e resmungou:

- Tá bem, tá bem, eu vou.

Então a garota calçou seu tênis Nike e saiu correndo.

O expletivo "Aaah", o comando "deixa eu ficar", a oração interrogativa "E para que tantos remédios?" (que coloca em dúvida a necessidade da atividade), o Atributo "vermelha de raiva" e o processo verbal "resmungou" (que expressam o descontentamento da menina) sinalizam a resistência da personagem em realizar a atividade solicitada. A pressa em cumprir a tarefa é indicada pelo processo comportamental "saiu correndo". O "tênis Nike" corrobora a representação da adolescente moderna, que não consegue ficar muito tempo sem usar a tecnologia, como se verifica no início da etapa Complicação, em que uma sequência de eventos é apresentada no caminho para a casa da avó:

(24) Chapeuzinho resolveu pegar um atalho pelo parque da cidade e lembrou que tinha um game portátil guardado no bolso e começou a jogar. Distraída, acabou entrando em um campo por perto.

Diferentemente das versões de Perrault e Grimm, o motivo da distração de Chapeuzinho, nessa versão contemporânea, não são as flores e os passarinhos do bosque, e sim "um game portátil” em que a menina começa a jogar. Ela só para quando gritos chamam sua atenção, dando início à fase problema e a uma nova aventura:

(25) Chapeuzinho começou a ouvir gritos desesperados vindo do norte. Ela chegou bem rápido no local.

Havia um lobo preso em uma armadilha, mas que na verdade era um farsante que fingia estar em apuros para roubar os pertences dos outros.

- Ai! Meu pé! Por favor, me ajude! Gritava o lobo, chorando "lágrimas de crocodilo".

O Atributo "farsante" e a oração comportamental "chorando lágrimas de crocodilo" realizam avaliações de julgamento em relação ao lobo, sinalizando para os ouvintes/leitores o caráter antiético do personagem. Tal caráter, porém, não é do conhecimento da menina, que acredita na conversa do lobo e dele se solidariza, a ponto de ela mesma levá-lo para a casa da avó depois de concluir que ele tivera ingerido os remédios que levava para a avó.

Diferentemente da versão dos Irmãos Grimm, em que a fase reflexão é usada para apresentar as intenções das personagens antes de executar as ações, em Chapeuzinho dos Olhos Vermelhos, são usadas as fases reação e eventos para apresentar as ações em execução.

Assim como nas versões clássicas, o lobo devora a avó, mas a motivação é diferente: as alucinações provocadas pelos remédios ingeridos, como se verifica em 26.

${ }^{9}$ A expressão “vermelha de raiva” marca uma intertextualidade com a estória Chapeuzinho Vermelho de Raiva, do brasileiro Mario Prata, publicado em 1970, pela Editora Globo.

Fuzer \& Weber|Chapeuzinho Vermelho em três versóes: análise de gênero na perspectiva sistêmico-funcional 
(26) Então, os sintomas do lobo pioraram. Ele começa a ter alucinações e imaginou a vovó como um sanduíche e "sem querer querendo" acabou devorando a vovó e depois fugindo para a floresta.

Um tom humorístico é dado à estória por meio das orações mentais "imaginou a vovó como um sanduíche" e "sem querer querendo", que representam a não intencionalidade do lobo em devorar a avó. A segunda oração, especialmente, faz uma intertextualidade com o bordão de um personagem de uma série de comédia televisiva muito popular na América Latina ${ }^{10}$, funcionando como mais um elemento do contexto contemporâneo trazido à estória.

Na sequência, a menina inicia uma perseguição ao lobo, na tentativa de recuperar a avó que se encontrava na barriga dele. A presença de um helicóptero e de uma emissora de TV também corroboram a representação do contexto social contemporâneo no qual narrador e personagens se mostram inseridos. A etapa Resolução é realizada com a ajuda não de um caçador como na versão de Grimm, mas do helicóptero que transportava uma equipe de reportagem para tevê. Nessa versão, podemos dizer que o caçador de animais é substituído por "caçadores de notícias", representados como Ator do processo "ajudaram" de que Chapeuzinho é Beneficiário:

(27) As pessoas da emissora que estavam no helicóptero ajudaram a Chapeuzinho a colocar o lobo dentro dele e o levaram ao hospital para remover a vovó de sua barriga. Chegando lá, os médicos deram anestésicos para o lobo dormir e eles poderem realizar a cirurgia.

A complicação se resolve quando a vovó é retirada da barriga do lobo, mas, dessa vez, não foi com uma tesoura nas mãos de um caçador, e sim por médicos em um hospital, representados como Ator dos processos materiais "deram anestésicos" e "realizar a cirurgia", indicando o tratamento humano concedido ao lobo.

A etapa Avaliação apresenta o "final feliz" típico dos contos de fada, expresso por atitudes das personagens tanto na voz do narrador quanto na voz das personagens:

(28) Logo após a cirurgia terminar, o lobo já fora dos sintomas colaterais, se desculpou com a Chapeuzinho e a vovó, e no final todos se deram bem.

- Sinto muito por tudo senhora, eu não quis devorá-la, eu estava meio "grogue" na hora, por ter comido seus remédios.

- Tudo bem meu filho, eu entendi, não precisa pedir desculpas a cada segundo, e eu não preciso mais daqueles remédios mesmo, já estou curada!

O processo verbal "se desculpou" e a oração mental emotiva "Sinto muito por tudo" contribuem para avaliar positivamente o comportamento do lobo e o representam mais como vítima (dos remédios) do que como vilão na estória. A reação da avó indicada pelo expletivo "Tudo bem" e pelo vocativo "meu filho", sinalizando avaliações de apreciação e afeto, bem como o final feliz para todos, inclusive para o lobo, o que marca a diferença marcante com o final das versões clássicas.

A estória termina com a etapa Coda, em que há referência ao contexto inicial da narrativa por meio da fala da avó:

(27) - E você minha neta querida? Não vai voltar para casa e ficar o dia todo grudada no tal computador?

- Não! Depois dessa aventura, quero é ficar longe dele e viver!

A circunstância de localização "para casa” e a oração relacional "ficar o dia todo grudada no tal computador", na pergunta da avó, retomam o cenário em que Chapeuzinho se encontrava no início da narrativa. O adjunto de negação "Não" e a oração mental desiderativa "quero é ficar logo dele e viver", na resposta da neta, explicitam a mudança de atitude dessa Chapeuzinho que tinha os

${ }^{10}$ El Chavo del Ocho é uma série mexicana de comédia de situação criada por Roberto Gómez Bolaños, transmitida pela primeira vez na televisão em 1971 . Até hoje faz parte da programação televisiva regular em vários países; no Brasil, traduzida como Chaves, é transmitida desde 1984 pelo Sistema Brasileiro de Televisão (SBT). 
"olhos vermelhos porque ficava muito tempo no computador". O processo comportamental "viver" representa uma consequência de ficar longe do computador, pressupondo que o uso demasiado de tecnologias impede experiências de vida. Essa reação pode ser interpretada como uma mensagem moralizante aos leitores em relação ao uso demasiado de tecnologias pelos jovens.

\section{CONSIDERACÕES FINAIS}

As análises realizadas neste estudo confirmam o princípio da teoria sistêmico-funcional de que o texto realiza o contexto e viceversa, já que o contexto influencia e é influenciado pela construção do texto conforme suas etapas. A análise das funções de transitividade associadas à avaliatividade possibilitaram identificar as etapas e fases do gênero instanciado em cada texto.

Chapeuzinho Vermelho, na versão dos Irmãos Grimm, e Chapeuzinho dos Olhos Vermelhos instanciam o gênero narrativa, uma vez que ambos os textos se organizam com as mesmas etapas: Orientação, Complicação, Resolução, Avaliação e Coda. As fases, porém, diferem-se, em grande parte, de uma narrativa para outra em função, principalmente, das variáveis do contexto de situação refletidas no texto. Embora na fase do cenário, na etapa Orientação, em ambas as versões, as protagonistas são apresentadas pelas mesmas atividades, na versão dos Irmãos Grimm, verificou-se uma imprecisão do espaço, do tempo e das personagens, ao passo que, na versão da aluna, as personagens e o espaço são nomeados. Também foram encontradas recorrências da fase reflexão na narrativa dos Irmãos Grimm, ao passo que, na reinvenção produzida pela aluna, foi mais recorrente a fase reação.

Já na versão mais antiga, de Charles Perrault, Chapeuzinho Vermelho é devorada pelo lobo, e a estória termina no Incidente, ficando o problema sem resolução. Em seguida, na etapa Interpretação, o narrador avalia o comportamento da menina e dá orientações aos leitores, evidenciando a instanciação do gênero exemplum.

Os resultados dessas análises serviram de subsídios para a elaboração de atividades de leitura e escrita de estórias, reunidas num ebook didático intitulado Ateliê de Textos para ler e reinventar estórias: do contexto ao texto (FUZER, 2017), destinado a aulas de leitura e produção textual para os anos finais do ensino fundamental.

\section{REFERENCIAS}

CANTON, K. Os contos de fadas e a arte. São Paulo: Prumo, 2009

CASTRO, R. Chapeuzinho dos olhos vermelhos. In: FUZER, C. WEBER, T. (Org). Modernizando os Clássicos. Santa Maria: Ateliê de Textos, CAL, DLV, UFSM, 2012.

FARENCENA, G. S. Artigo de opinião como macrogênero: relações lógico-semânticas na perspectiva sistêmico-funcional. 2015.234 f. Tese (Doutorado em Letras) - Programa de Pós-Graduação em Letras, Universidade Federal de Santa Maria, Santa Maria, 2015.

FUZER, C. Ateliê de textos: Práticas orientadoras no processo de produção e avaliação de textos na perspectiva textual-interativa. Projeto de ensino e extensão Registro GAP/CAL nº 029622. Santa Maria: CAL, UFSM, 2011.

. Leitura e escrita em Língua Portuguesa na perspectiva sistêmico-funcional. Projeto pesquisa Registro GAP/CAL n 037375. Santa Maria: CAL, UFSM, 2014.

Realizações linguísticas e instanciação de gêneros na perspectiva sistêmico-funcional. DELTA, v. 34, n.1, p.269-304, 2018. Disponível em: < http://dx.doi.org/10.1590/0102-445082775369453342>. Acesso em: 10 jun. 2018

Fuzer \& Weber|ChapeuzinhoVermelho em três versóes: análise de gênero na perspectiva sistêmico-funcional 
FUZER, C. (Org.). Ateliê de Textos para ler e reinventar estórias: do contexto ao texto. Série Cadernos de Extensão, Cultura, n. 1, Santa Maria: Editora da Pró-Reitoria de Extensão da UFSM, 2017. [E-book]. Disponível em: < https://repositorio.ufsm.br/handle/1/11535>. Acesso em: 10 jun. 2018.

FUZER, C.; GERHARDT, C; WEBER, S. Etapas e fases da narrativa em O Pequeno Polegar: análise de gênero na perspectiva sistêmico-funcional. Cadernos do IL, Porto Alegre, n. 52, p. 162-181, dez. 2016.

GEHRKE, N. A. Foto do dia ou microcrônica verbo-visual? Um gênero na perspectiva da Escola de Sydney. 2015.212 f. Tese (Doutorado em Letras) - Programa de Pós-Graduação em Letras, Universidade Federal de Santa Maria, Santa Maria, 2015.

GRIMM. Chapeuzinho Vermelho. Trad. Nilce Teixeira. In: PERRAULT, C.; GRIMM, et al. Contos de Fada. Rio de Janeiro: Zahar, 2010 [1857].

HALLIDAY, M. A. K. An introduction to functional grammar. London: Arnold, 1985.

HALLIDAY, M. A. K.; HASAN, R. Language, context and text: aspects of language in a social-semiotic perspective. Oxford: Oxford University Press, 1989.

HALLIDAY, M.A.K. Methods - techniques - problems. In: HALIDAY, M.A.K.; WEBSTER, J.J. (Ed.). Continuum Companion to Systemic Functional Linguistics. London and New York: Continuum International Publishing Group, 2009. p. 59-86.

HAlLIDAY, M. A. K.; MATTHIESSEN, C. M. I. M. Halliday's Introduction to Functional Grammar. New York / London: Routledge, 2014.

. An introduction to functional grammar. London: Edward Arnold, 2004.

HERBSTER, A; TAVARES, M. Recolorindo a Chapeuzinho: novos temas e intertextualidade. Revista Enlije, Campina Grande, v.1, n.2, p. 51-69, 2014.

HYON, S. Genre in three traditions: Implications for ESL. TESOL Quarterly, v. 30, n. 4, p. 693-722, 1996.

HUSTON, N. A espécie fabuladora. Porto Alegre: L\&PM, 2010.

LABOV, W.; WALETZKY, J. Narrative analysis: oral versions of personal experiences. In: HELM, J. (Ed.). Essays on the Verbal and Visual Arts. Seattle: University of Washington Press, 1967.

MARTIN, J. R. Types of Writing in Infants and Primay School. In: MARTIN, J.R. Genre Studies. Edited by Wang Zhenhua. Collected Works of J. R. Martin, v. 3. Shanghai: Shanghai Jiao Tong University Press, 2012 [1984]. p. 09-30.

; PLUM, G. Construing Experience: Some Story Genres. In: MARTIN, J.R. Genre Studies. Edited by Wang Zhenhua. Collected Works of J. R. Martin, v. 3. Shanghai: Shanghai Jiao Tong University Press, 2012. p. 152-160.

MARTIN, J.; ROSE, D. Genre Relations: MappingCulture. London: Equinox, 2008.

MARTINS, K. Chapeuzinho: uma narrativa e várias leituras. Revista Enlije, Campina Grande, v.1 , n. 2, 2014.

_.Genre and Literacy-Modeling Context in Educational Linguistics. Annual Review of Applied Linguistics, v. 13, p. 141-172, 1992. 
MARTIN; WHITE, P. R. R. The language of evaluation: appraisal in English. London: Palgrave, 2005.

MEREGE, A. Os contos de fadas: origens, história e permanência no mundo moderno. São Paulo: Claridade, 2010.

MOTTA-ROTH, D; HEBERLE, V. A short cartography of genre studies in Brazil. Journal of English for Academic Purposes, xxx, p. 22-31, 2015.

PRATA, Mario. Chapeuzinho Vermelho de Raiva. Rio de Janeiro: Editora Globo, 1970. Disponível em: https://marioprata.net/literatura-2/literatura-infantil/ chapeuzinho-vermelho-de-raiva/

PERRAUlT, Charles. Contos de Perrault. Tradução de Maria Stela Gonçalves. São Paulo: Paulus, 2005 [1695].

RODRIGUES, A. Análise da ideação, avaliatividade e tematização em narrativas de aprendizagem de línguas. Delta, São Paulo, v. 26, n. 2, p. 255-288, 2010.

ROSE, D.; MARTIN, J. Learning to write, reading to learn: Genre, Knowledge and Pedagogy in the Sydney School. London: Equinox, 2012.

ROTHERY, J. Story Writing in Primary School: Assessing Narrative Type Genres. PhD Thesis, University of Sydney, Sydney, 1990.

ROTHERY, J.; STENGLIN, M. Entertaining and instructing: exploring experience through story. In: CRHISTIE, F.; MARTIN, J.R. (Ed.). Genre and Institutions: Social Processes in the Workplace and School. London: Pinter. 1997. p. 134-160.

SANTOS, T. S. Nos caminhos da natureza: análise de gêneros na perspectiva sistêmico-funcional em livros didáticos de ciências naturais. 2016. 295 f. Tese (Doutorado em Letras) - Programa de Pós-Graduação em Letras, Universidade Federal de Santa Maria, Santa Maria, 2016.

SOARES, P. A arte de escrever histórias. Baueri: Amarilys, 2010.

TATAR, M. Contos de fadas: edição comentada e ilustrada. Rio de Janeiro: Zahar, 2004.

TAVARES, F. SILVA, S. Leitura e intertextualidade nas diferentes versões de Chapeuzinho Vermelho. In: CÍRCULO FLUMINENSE DE ESTUDOS FILOLÓGICOS E LINGUÍSTICOS, 8.. 2013. Rio de Janeiro. Anais da Revista Philologus, Ano 19, n. 57. Rio de Janeiro: CiFEFiL, set./dez.2013.

THOMPSON, G.; THETELA, P. The sound of one hand clapping: the management of interaction in written discourse. Text, n.15, v.1, p. 103- 127, 1995.

VOlObUEF, K. Contos de fadas dos Irmãos Grimm. Carta na Escola. \#Carta, 10 jan. 2013. Disponível em: $<$ https://www.cartacapital.com.br/educacao/carta-fundamental-arquivo/contos-de-fadas-dos-irmaos-grimm>. Acesso em: 27 jun. 2017.

WEBSTER, J. J. An introduction to continuum companion to Systemic Functional Linguistics. In: HALLIDAY, M. A. K.; WEBSTER, J. J. Continuum companion to Systemic Functional Linguistics. New York: Continuum, 2009. 